\title{
Organization of a Unified State Housing and Demographic Policy as a Condition for Sustainable Development of Cities and Settlements
}

\author{
A.B. Assylbayev ${ }^{1,}$, A.N. Asaul ${ }^{2}$, K.N. Niiazalieva ${ }^{1}$, M.A. Asaul ${ }^{3}$, G. F. Shcherbina ${ }^{2}$ \\ ${ }^{1}$ State educational institution of higher professional education Kyrgyz-Russian Slavic University named after the first \\ President of the Russian Federation B.N. Yeltsin, Bishkek, Kyrgyz Republic \\ ${ }^{2}$ Federal State-Owned Publicly-Funded Institution of Higher Education St. Petersburg State University of \\ Architecture and Civil Engineering, St. Petersburg, Russia \\ ${ }^{3}$ Saint Petersburg State University of Civil Aviation, Saint Petersburg, Russia \\ ${ }^{*}$ Corresponding author.Email: aidaras73@mail.ru
}

\begin{abstract}
The relevance of the study is due to the alarming rates of disproportionate development of housing construction and demographic growth in Russia and the Eurasian Economic Union (EAEU). The non-harmonious development of the two systems leads to formation of regions with a demographic failure and to the restriction of access to decent and cheap housing. Such a picture forms negative social behavior, leading to the limitation of the birth rate of third and subsequent children. In the paper, the correlation analysis method identifies the relationship between the dynamics of new development and the dynamics of the population of Russia and the EAEU, which is 0.728 and 0.853 , respectively. Recommendations are offered for improving the state housing and demographic policy within the framework of an international project of the Council of the Eurasian Economic Commission and on the basis of the identified links between the rhythms of housing commissioning and population growth in the EAEU and Russia in the framework of achieving the eleventh goal of the UN Resolution on Sustainable Development.
\end{abstract}

Keywords: population size, housing demography, housing commissioning, correlation, development rhythm, population rhythm, trend line.

\section{INTRODUCTION}

In 2015, it was adopted UN Resolution "Transforming the World. The Agenda for Sustainable Development up to 2030" [1], which approved the main goals of world development, including improving the quality of life of the world's population. The eleventh goal is aimed at the development of comfortable cities and settlements. Achieving this goal is impossible without arranging a unified state housing and demographic policy both in individual states and within the framework of some international association. Here the unified economic policy of the Eurasian Economic Union (EAEU) plays an important role in achieving the Sustainable Development Goals (SDGs) of the countries participating in the international association, which have their own contribution to the overall demographic and housing picture of the Union, however, the share of Russia is more impressive and basic even with the expected demographic crisis in the country, therefore, we will consider these issues for the Russian Federation.

In the study of the scientific school "Methodological problems of the effectiveness of regional investment and construction complexes as a self-organizing and selfgoverning system", the problems of investment and construction activities [2-4] are central, especially the theme of sustainable development [5-8] of business entities in the investment and construction sphere. Social and spatial aspects, the quality of the urban environment are highlighted in the papers [9-12], a significant place in the implementation of the concept of improving the quality of life of the population, as well as the variety of problems of housing policy to be solved, is given in the papers [13-15].

Based on the analysis of the growth in the scope of housing commissioned [16-17], three forecast scenarios for the growth of annual commissioning of the total area 
of residential buildings in the Russian Federation are presented [18]. Using the obtained data, as well as the dynamics of housing commissioning and studying the dynamics of the population of not only Russia, but also the EAEU, in this paper, the tightness of the relationship between demographic development and the rate of housing construction is determined. Studies in the EAEU and Europe are devoted to the establishment of the interdependence between the living conditions of citizens and their demographic manifestations [19-22]. Scientists dealing with demography and housing issues argue that the housing factor in demographic development is underestimated and has the potential for scientific research [23-28]. The high degree of interdependence of the data obtained based on the countries with the best indicators of the growth rates of housing construction and demographic development provides the basis for formation of the unified housing and demographic policy of the EAEU.

The relevance of identifying the close relationship between the active activity of housing construction and a slight increase in the population of the EAEU and Russia is due to the aggravating disproportionate development of rhythms between demographic growth and the commissioning of housing both in the EAEU and in Russia. Such an inharmonious dynamics of the rhythms of population development and housing commissioning may be the basis for inappropriate funding of housing between households of different incomes and formation of an additional restriction on equal access to decent housing conditions, which does not contribute to increase in the quality of life of the population.

It shall be noted that the very fact of rearranging the correlation interdependence between demographic phenomena and the living conditions of the citizens of the EAEU will make it possible to develop an effective unified strategy for demographic and housing development in the member states of an international association like the EAEU. Wherein, a decent housing situation for the citizens of the EAEU will create a basis for formation of positive dynamics of demographic development by eliminating and reducing factors that negatively affect the dynamics of population reproduction and migration. Currently, the work is performed to develop international projects of the Council of the Eurasian Economic Commission (EEC) "On ensuring the functioning of a single market for services in the construction sector" and "On the macroeconomic situation in the member states of the Eurasian Economic Union and offers for ensuring sustainable economic development". In this regard, the relevance and importance of the topic, focused on the organization of a unified state housing and demographic policy, as a condition for the sustainable development of cities and settlements, is concentrated in the purpose hereof.
The purpose of the paper is to determine the relationship between the rhythms of housing commissioning and population growth of the Eurasian Economic Union and Russia in the framework of achieving the eleventh goal of the UN Resolution on Sustainable Development.

\section{Target tasks:}

- examine separately and investigate the tightness of the relationship between the speakers commissioning the housing in the EAEU and Russia;

- also, study separately and explore the relationship between the dynamics of the average annual population in the EAEU and Russia;

- to simulate and correlate the dynamics of changes in the housing commissioning index across the EAEU and Russia with the identification of the degree of correlation,

- to consider the revealed correlation between the rhythms of housing commissioning and the growth of the average annual population in the EAEU and Russia;

- to formulate recommendations for creation of the unified housing and demographic policy for all EAEU member states.

Object of research: development of comfortable cities and settlements in the concept of sustainable development.

Subject of research: the dynamics of the rhythm of the population and the commissioning of housing in the region of their disproportionate development.

\section{MATERIALS AND METHODS}

The methodology for developing the topic is based on general methods of systematizing, analyzing and synthesizing information, methods of classifying and obtaining information, methods of econometric analysis of statistics for the Eurasian Economic Union (The website of the Eurasian Economic Union, https://eaeunion.org/\#services). Namely, a correlation analysis was applied to identify the tightness of the relationship between demographic development and housing development in the EAEU and Russia.

\section{RESULTS AND DISCUSSION}

With formation of the Eurasian Economic Union, it became necessary to study the quality of life of the entire Union population, including the quality of housing conditions as one of the factors in the quality of life. Wherein, it is necessary to consider the disproportionate demographic development and the scope of new construction in the member countries of the union. Kyrgyzstan and Kazakhstan show strong population growth, Russia a slow decline, and active population decline is observed in Belarus and Armenia. Due to the 
dynamics of the population of Kyrgyzstan, Kazakhstan and Russia across the EAEU, there is a sluggish growth in the population. Over the same period, an active growth in the scope of construction works is observed in Russia, Kazakhstan and Belarus, which has a positive effect on the entire picture of the EAEU in terms of construction. However, Russia in this international association is represented by the absolute majority of the population and the scope of new construction. In this regard, their dynamic picture of the commissioning of a new dwelling is quite close and identical (see. Figure 1. The diagram is compiled according to the EAEU statistics for the period from 2005 to 2019 (EAEU statistics. Access mode: http://www.eurasiancommission.org).

Figure 1 shows that the dynamics of housing commissioning in Russia occurs in a cyclical manner with the observed periods of recession and recovery. So, from 2005 to 2008 , the first period of growth is observed, and then a decline until 2011 and further growth until 2015. Since 2015, there has been a second decline in the scope of housing commissioned. Roughly the same picture is observed in the EAEU, but with brighter periods of recession and recovery. The identity of the cyclical development of the scopes of housing commissioning between the EAEU and Russia is proved by the functions of describing the trend line. In both cases, it is difficult to describe, which is characteristic of the wave-like behavior of the trend line and has an uncertain reliability of the description equal to within 8487 percent of the reliability. Therefore, the EAEU trend line is described by the function $y=-0.0112 x^{3}+0.1344 x$ $2^{2}+3.4445 x+54.181$ with an approximation coefficient $\mathrm{R}^{2}=0.8777$, which corresponds to $87 \%$ accuracy. In Russia, a trend line closer to reality is described by function $y=-0.0195 x^{3}+0.3197 x^{2}+1.7813 x+46.158$ with an approximation of $\mathrm{R}^{2}=0.8394$, which is only $84 \%$ reliable. The identity of the development of new construction in the EAEU and Russia is proved by the high correlation indicator of the relationship, equal to Correl $=0.994817588$, which indicates a straight-line high dependence of these two indicators of housing commissioning.

The next proof of the identity of the picture of the dynamics of housing construction in the EAEU and Russia is the similar dynamic behavior of the housing commissioning indices (see. Figure 2. The diagram is compiled according to the EAEU statistics for the period from 2005 to 2019 (EAEU statistics. http://www.eurasiancommission.org).

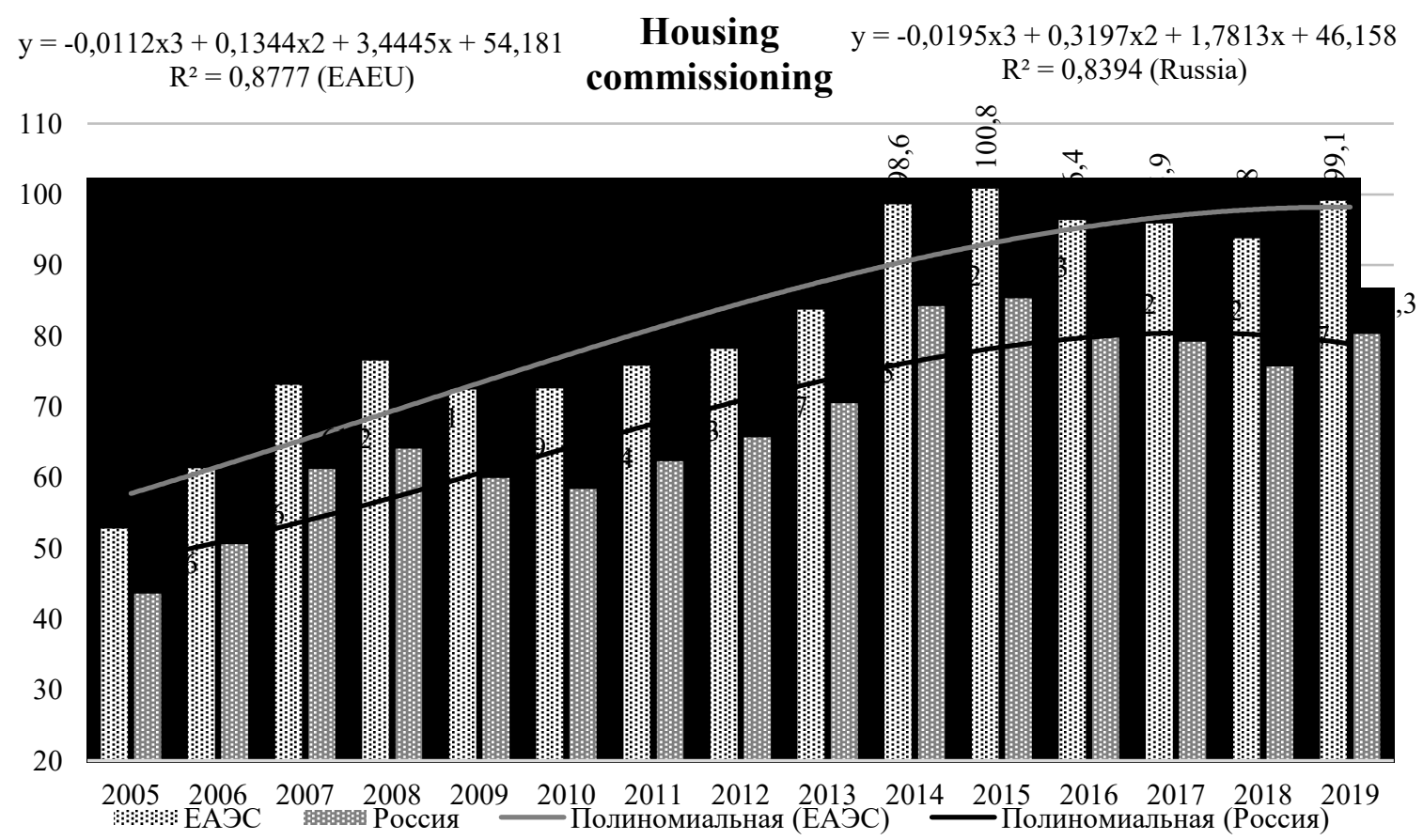

Figure 1 Housing commissioning across the EAEU and Russia (million $\mathrm{m}^{2}$ )

EAЭC - EAEU

Россия - Russia

Полиномиальная - Polynomial 


\section{Housing commissioning index (in \% to the previous}

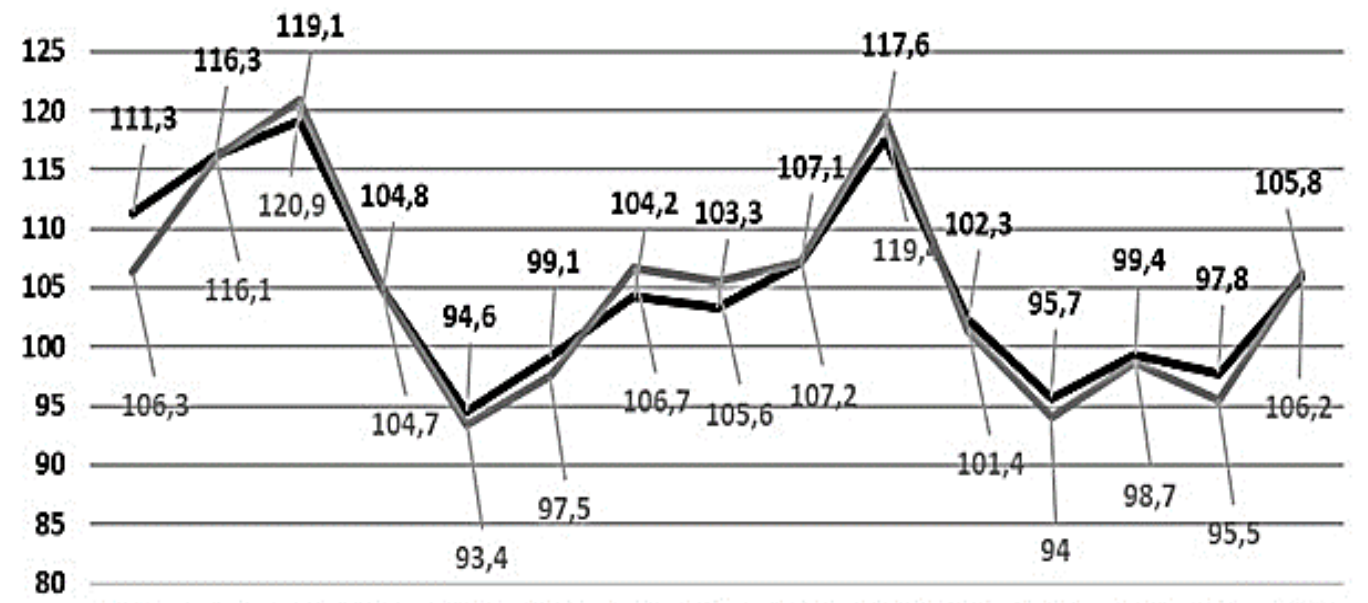

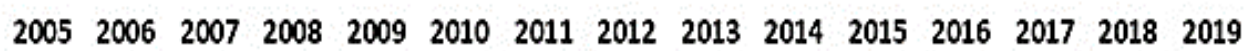

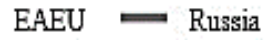

Figure 2 Index of housing commissioning in the EAEU and Russia (in \% to the previous year)

Visually, from Figure 2, there is a similarity in the behavior of housing commissioning indices in Russia and the EAEU over the analyzed fifteen-year period of the Union's existence. Correlation analysis also showed a high straight-line relationship between the two index indicators and is equal to Correl coefficient = 0.976211317 , which undoubtedly confirms our statement about the similarity of the development indicators of Russia and the EAEU on the housing issue. Meanwhile, the dynamics of the population is also important for determining the quality of life of the population and identifying the degree of relationship between the housing and demographic development of the EAEU and Russia. Since Russia has an absolute numerical advantage of its population in the EAEU, it is necessary to find out how the dynamics of the population of Russia correlates with the dynamics of the population of the EAEU (see Figure 3. The diagram is compiled according to the EAEU statistics for the period from 2005 to 2019 (EAEU statistics. http://www.eurasiancommission.org/).

Visually, from Figure 2, there is a similarity in the behavior of housing commissioning indices in Russia and the EAEU over the analyzed fifteen-year period of the Union's existence. Correlation analysis also showed a high straight-line relationship between the two index indicators and is equal to Correl coefficient = 0.976211317 , which undoubtedly confirms our statement about the similarity of the development indicators of Russia and the EAEU on the housing issue. Meanwhile, the dynamics of the population is also important for determining the quality of life of the population and identifying the degree of relationship between the housing and demographic development of the EAEU and Russia. Since Russia has an absolute numerical advantage of its population in the EAEU, it is necessary to find out how the dynamics of the population of Russia correlates with the dynamics of the population of the EAEU (see Figure 3. The diagram is compiled according to the EAEU statistics for the period from 2005 to 2019 (EAEU statistics. http://www.eurasiancommission.org/).

Figure 3 shows that the growth of the EAEU population is growing steadily and has a confident quadratic growth function $y=45173 x^{2}-67068 x+2 E+$ 08 with a high confidence factor $\mathrm{R}^{2}=0.9506$, which corresponds to more than $95 \%$ probability. Wherein, the dynamics of growth in the population of Russia does not show a steady growth dynamics, but most likely a period of a stable population with the expectation of a picture of a decline in the number of citizens in the future. Therefore, the trend line, which is described by the function $y=-0.0195 x^{3}+0.3197 x^{2}+1.7813 x+46.158$, has a low reliability of the description and corresponds to $\mathrm{R}^{2}=0.8394$ or equal to $84 \%$ confidence. However, to date, the indicators of population growth in the EAEU and Russia have a high dependence equal to Correl $=$ 0.97752372, which confirms the straightforward dependence of the indicators of the EAEU and Russia. Also, the growth rates of the population of the EAEU and Russia from 2005 to 2019 have a high connection density equal to Correl $=0.991300167$ (see Figure 4. The diagram is compiled according to the EAEU statistics for the period from 2005 to 2019 (EAEU statistics. http://www.eurasiancommission.org).

Figure 4 in 2015 clearly shows the peak in the rate of population growth both in the EAEU and in Russia. In general, the dynamics of the population rate is quite calm and has a slow development. 
If we take the course of development of the population in the EAEU, then here the dynamics are more stable and have the form of a pronounced trend of growth in the population. At the same time, the growth rates are different by periods, but in general, the dynamics of demographic growth is stable. With a high confidence rate of $95 \%\left(\mathrm{R}^{2}=0.9506\right)$, the trend line is displayed as a positive function $y=45173 \mathrm{x}^{2}-67068 \mathrm{x}+2 \mathrm{E}+08$. Based on it, we can assume an increase in the population of the EAEU for the next forecast period.

In addition, when comparing the graphs and determining their possible interdependence, we carried out a correlation analysis in the Correl program. This analysis confirmed the statement that there is a relationship between the two factors and the correlation coefficient was Correl $=0.853$. The correlation coefficient turned out to be positive, which fully corresponds to the academic theory of supply and demand in the housing market: the higher the demand for housing, the higher its supply in the market. It shall be noted that the demand in the housing market is mainly formed by households, and not individually by each citizen, but at the same time, an increase in the population leads to an increase in the number of households, marriages and divorces. But at the same time, housing has its own peculiarity, which lies in the time lag between the demand for it and its actual supply. This time lag depends on the speed of construction of residential buildings and the pace of their commissioning, and sometimes this stage does not meet market demand. During this period, there is a shortage of housing, which leads to active filtration within the housing market, which in turn depends on the ability to pay and the growth rate of each class of the population.

\section{CONCLUSION}

In the economies of the EAEU and Russia, there are unresolved issues of disproportionate development of demographic and housing phenomena. We consider it correct to state that the demographic situation in the EAEU countries, including in Russia, is associated with the availability of housing and the quality of housing conditions. On the example of the EAEU and Russia, a connection was revealed between the processes in the housing and demographic sector of the economy. Definitely, this connection is not only mutual, but also has all the signs of mutual influence and determination, thereby emphasizing the complexity and interdisciplinarity of such relations between the two sectors of the economy. Wherein, it is necessary to consider that from a scientific point of view, it is important to single out such interdependence in a separate scientific direction - housing demography.

Therefore, the housing factor in demographic processes must be recognized as a subject area of study in housing demography [29].

\section{The number of resident population on average per year across the EAEU and Russia (people)}

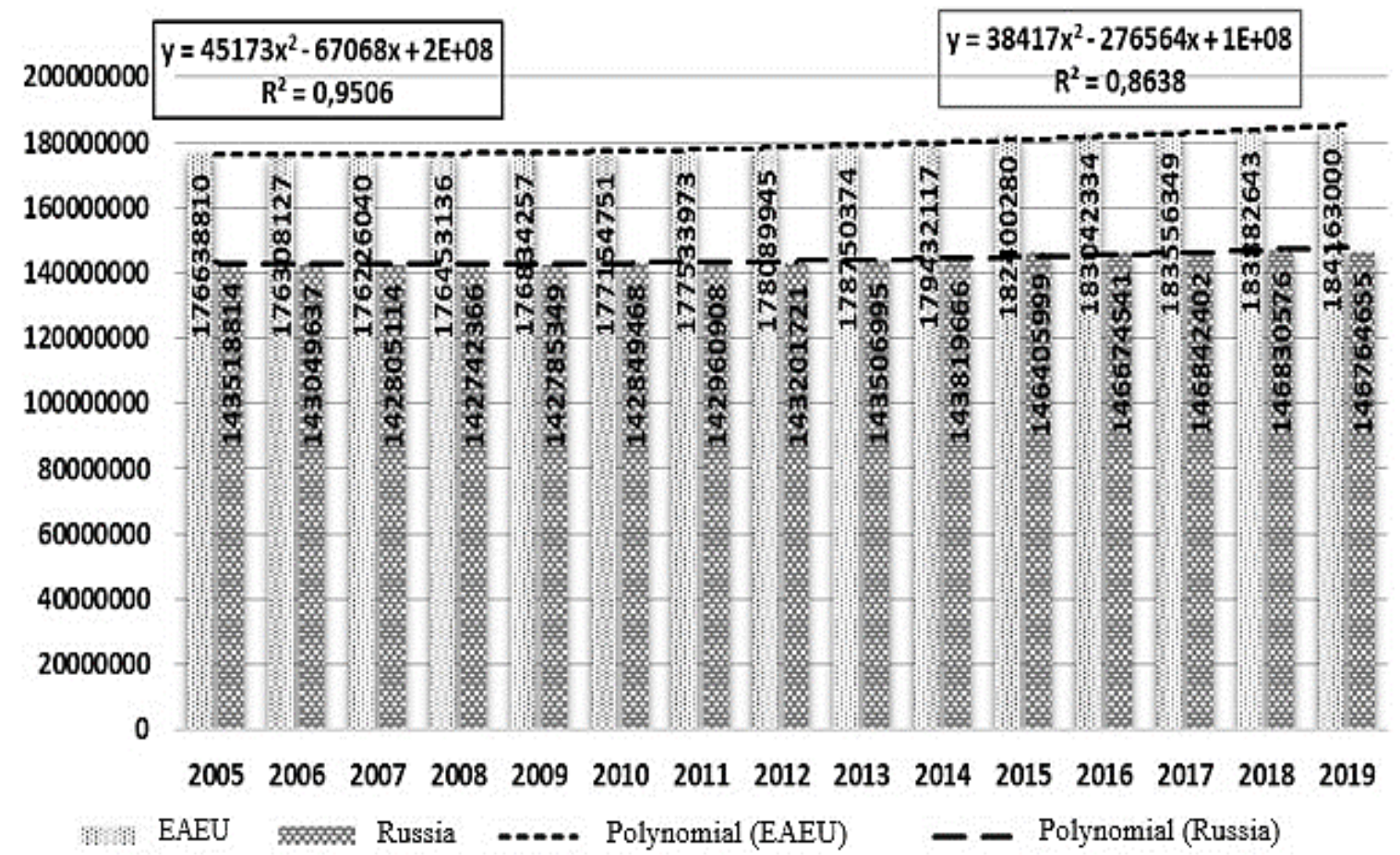

Figure 3 The number of resident population on average per year across the EAEU and Russia (people). 


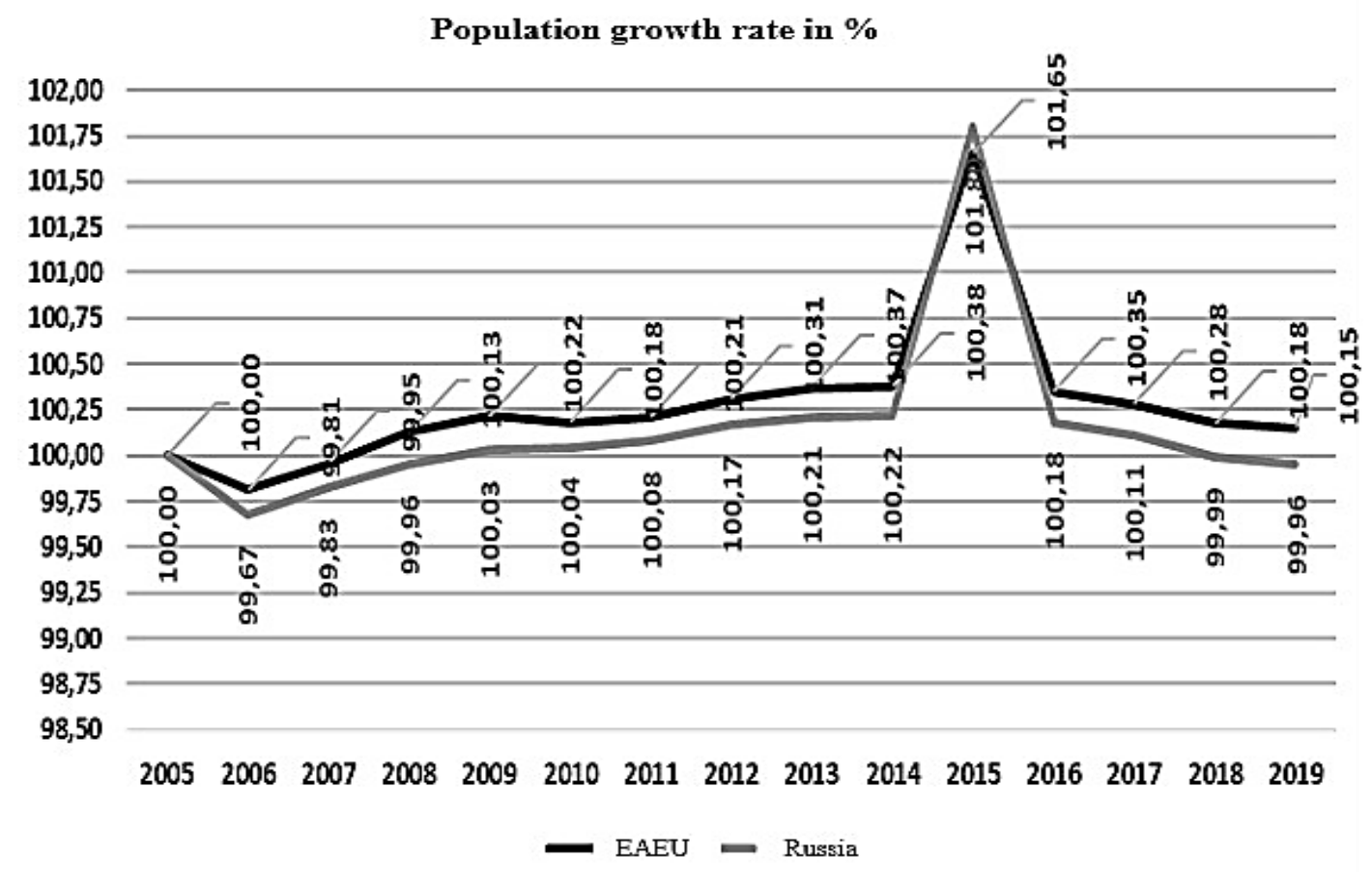

Figure 4 Population growth rate of the EAEU and Russia (in \%).

\section{RECOMMENDATIONS}

Create the unified housing and demographic strategy within the framework of the comprehensive program for economic development. For a detailed planning of the strategy of housing and demographic policy, it is important to take into account the following:

- to monitor the qualitative and quantitative distribution of housing in all classes of Russian society;

- to conduct surveys of the qualitative composition of housing in accordance with the unified EAEU standards, in order to form a unified assessment system;

- to introduce a program to support households with three or more children for the purchase of housing;

- renovation and state filtration of housing in cities with a million inhabitants;

- across the EAEU, to stimulate the construction of housing for migrants in order to attract them to areas with a demographic failure;

- to activate and stimulate public-private partnership programs in housing construction;

The actual substantiations and results of the interdependence of the dynamics of new housing construction with the dynamics of the population are provided, which is a clear sign of the need to further identify the relationship between housing and demographic processes within housing demography as an independent scientific study.

\section{ACKNOWLEDGMENTS}

The authors express their sincere gratitude for the help provided during the work on the article to the team of the scientific school "Methodological problems of the effectiveness of regional investment and construction complexes as a self-organizing and self-governing system".

\section{REFERENCES}

[1] Achieving the Sustainable Development Goals in the Region of the Eurasian Economic Union. Statistical abstract. Eurasian Economic Commission, 2019, p. 95.

[2] A.N. Asaul, Problems of investment and construction activities. Scientific works of the VEO of Russia 190 (2015) pp. 253-266.

[3] A.N. Asaul, A.A. Gorbunov, D.A. Zavarin, Features of investment planning of innovative investment and construction projects (part 1). Economics of construction 5 (2015) pp. 30-39.

[4] A.N. Asaul, A.A. Gorbunov, D.A. Zavarin, Features of investment planning of innovative investment and construction projects (part 2). Economics of construction 1(37) (2016) pp. 32-43.

[5] M.A. Asaul, E.I. Rybnov, Using the tools of the theory of catastrophes for modeling the 
sustainability of entrepreneurial structures. Bulletin of civil engineers 3(24) (2010) pp. 141-145.

[6] M.A. Asaul, Sustainability management of business structures. ANO IPEV, 2008, p. 285. DOI: https://doi.org/Project30210.17513/.

[7] M.A. Asaul, Maintaining the stability of the construction organization. Economic revival of Russia 4(18) (2008) pp. 53-59.

[8] M.A. Asaul, Ensuring the sustainability of entrepreneurial structures in the investment and construction sector. Dissertation for the degree of Doctor of Economics. GOUVPO "St. Petersburg State University of Architecture and Civil Engineering". St. Petersburg, 2009, p. 349.

[9] S. A. Ershova, Orlovskaya, The Concept of SocioSpatial Development as the Basis of Economic Security of Megalopolises, In: IOP Conference Series: Materials Science and Engineering, 753(2) (2020), p. 022087

[10] E. V. Ilina, A. L. Romanova, O. V. Maksimchuk, A. V. Voronin, Development of the construction industry in the context of import substitution. Russian experience 38(48) (2017) p. 18.

[11] R. Mavlioutov, M. Belyaev, K. Borisova, Reengineering of manufacturing processes in the construction organization, In: IOP Conference Series: Materials Science and Engineering, 2020, p. 012120 .

[12] Khrustalev, Formation of the Sustainable Development Strategy of the Enterprises of Construction Complex and Housing Utility Services, 2009.

[13] E. Aleksandrova, V. Vinogradova, G. Tokunova, Integration of technologies in the field of construction in the Russian Federation. Engineering Management in Production and Services 11(3) (2019) pp. $38-47$.

[14] A. Yu. Levin, A.M. Platonov, Energy supply of isolated territories in the context of attracting investment and developing the region's economy. The economy of the region 16(3) (2020) p. 884895. DOI: https://doi.org/10.17059/ekon.reg.2020-3-16.

[15] J. Levin, G. Shcherbina, E. Trushkovskaya, Proactive mechanisms for response to risks of business entities in investment and construction activities, In: E3S Web of Conferences 2nd International Scientific Conference and Civil Engineering (STCCE - 2021), 2021, p. 05007. DOI: https://doi.org/10.1051/e3sconf/202127405007.
[16] G.M. Zagidullina, A.I. Romanova, O.A. Kleshcheva, I.E. Faizullin, R.M. Ivanova, Peculiarities of housing construction development in the region. Middle East Journal of Scientific Research 16(4) (2013) pp. 490-495.

[17] N.A. Polovnikova, N.V. Chepachenko, M.N. Yadenko, Study and evaluation of the competitiveness potential of the organizations in the construction industry, In: Materials Science Forum, 2018, pp. 1178-1181.

[18] P. B. Lyulin, N. V. Chepachenko, Trends of housing construction in Russia and medium-term forecast. Problems of forecasting 3(174) (2019) pp. 111-117. DOI: https://doi.org/10.1134/s107570071903005.

[19] A.B. Assylbayev, Issues of the relationship between the processes of housing provision and changes in the age structure of the population in the EAEU countries, In: Demographic aging of the population: threats and new realities: Materials int. scientificpractical. Conf., X All-Russian Science Festival NAUKA 0+, "Econ-Inform", 2020, pp. 13-31.

[20] C. H. Mulder, B. Ten Hengel, J. Latten and M. Das, Relative resources and moving from the joint home around divorce. Journal of Housing and the Built Environment 27(2) (2012) pp. 153-168. DOI: https://doi.org/10.1007/s10901-011-9250-9.18.

[21] Z.K. Ayupova, D.U. Kussainov, W. Nagan, Novelties in the Legal System as Motive Force of Legal Integration, News of the National Academy of Sciences of the Republic of Kazakhstan. Series of Social and Human Sciences 1(323) (2019) pp. 102106. DOI: https://doi.org/10.32014/2224-5294.15.

[22] Y.A. Amireev, A.K. Daurenbekov, Zh.Y. Beisekova, "Statistics Onerkusip" Esepter zhinagy. ZhShS "Knowledge-Polygraph" Almaty. AESA, 2021.

[23] S.V. Ryazantsev, Migrant workers as a resource for the demographic development of Russia and the Republic of Kazakhstan. Bulletin of the National Academy of Sciences of the Republic of Kazakhstan 2, 390(2021) pp. 204 212. DOI: https://doi.org/10. 32014/2021.2518-1467.71.

[24] A.B. Assylbayev, Formation of housing demography in the general theory of population. Bulletin of the Tajik National University. A series of socio-economic and social sciences 3 (2018) pp. 91-96.

[25] A.B. Assylbayev, Housing demography in the system of demographic sciences: theoretical and methodological aspect. Competitiveness in the 
global world: economics, science, technology 11(58) (2017) pp. 1505-1508.

[26] A.B. Assylbayev, Analysis of the correlation between the housing sector and the natural process of population movement. Bulletin of the University (Russian-Tajik (Slavonic) University) 2(62) (2018) pp. 146-159.

[27] A.B. Assylbayev, Problems of choice of dwelling by quality and area of households with unequal incomes. Bulletin of the Tajik National University. A series of socio-economic and social sciences 3 (2018) pp. 15-20.

[28] A.B. Assylbayev, Formation of housing demography in the general theory of population. Bulletin of the Tajik National University. A series of socio-economic and social sciences 3 (2018) pp. 91-96.

[29] A.B. Assylbayev, Housing demography in the system of demographic sciences: theoretical and methodological aspect. Competitiveness in the global world: economics, science, technology 11 (58) (2017) pp. 1505-1508. 